\title{
Leprosy Control in the Southern Province of Zambia*
}

\author{
S. L. GAUNTLETT \\ Formerly Chief Medical Officer, The Salvation Army Hospital, Chikankata, Zambia†
}

\section{INTRODUCTION}

In any developing country medical policy, as with any other departmental policy, needs to be viewed against the economic background. There are the basic facts of a relatively low per capita annual income, and the many other fields of development that vie for priority consideration, such as education, agriculture, or defence. There is obvious interaction between different departments, so that progress in education and agriculture, for example, is bound to benefit the health of the nation. In considering the health budget, an order of priority must be based upon the most pressing needs, the impact that any given measure will make upon a problem (including the interaction it will have on other health problems), the practicability of a project in terms of available trained staff, the availability of materials, and acceptability by the population, as well as some calculation of the likely return from money and time invested.

Zambia is one of the more affluent of the developing countries today, with a per capita average annual income of $£ 118$, compared with Nigeria $£ 48$ or E. Africa $£ 28$ (U.K. $£ 560$ ), but when our control programme began Zambia was part of the Federation of Rhodesia and Nyasaland, most of its revenue from copper was leaving the country for Britain or for Federal use, and very little money was available for health development. Even today, of the $£ 339$ million recurrent expenditure planned in the current 4-year National Development Plan only £9 million is allocated to health (as compared with

*Received for publication 22 July, 1969.

†Present address: The William Booth Memorial Training College, Denmark Hill, London, S.E.5.
$£ 40$ million for education). We had, therefore, to do everything possible to tackle the problem of leprosy without any additional funds being available, at least on the provincial level. In 1952 a national plan for the treatment and control of leprosy was drawn up by an ad hoc committee called by the Director of Medical Services and comprising both Government and mission medical officers interested in leprosy. Although this plan was initially accepted by the Government, after wider discussion it became apparent that differences in geography, communications, tribal customs, and distribution of the disease made it desirable to plan separate schemes for each of the 6 different provinces of the country. At a later date I was asked to accept responsibility for the co-ordination of leprosy treatment and control in the Southern Province of Zambia under the Provincial Medical Officer (P.M.O.) and the territorial leprologist. That a mission medical officer should be given what is usually thought of as a government responsibility was not considered unusual in Zambia, for the missions and the Government have for many years worked in the closest cooperation; the position was, of course, an honorary one, there being no funds available anyway!

\section{ORGAN:ZATION}

The Southern Province covers an area of $33,000 \mathrm{sq}$. miles $(85,000 \mathrm{sq}$. $\mathrm{km}$.). It is bounded on the north by the Kafue river, in the east and south by the Zambesi, while in the west and south-west it borders on Barotseland and the Caprivi Strip. The railway line from Rhodesia in the south, through Livingstone and up to the 
copperbelt, traverses the province from S.W. to N.E. and on it are situated 3 towns with populations of between 3000 and 7000, as well as Livingstone, the provincial centre, with a population of 34,000. Apart from light industries in the larger towns the province is almost an entirely agricultural area, with a thriving fishing industry now in the Zambesi (Gwembe) Valley on the banks of the Kariba lake. This latter development has taken place since the completion of the Kariba hydroelectric dam in 1959 and altered the pattern of disease amongst a previously backward valley tribe. The total population of the province is slightly under half a million (population density: 14 per sq. mile or about 5.4 per sq. $\mathrm{km}$.), the majority belonging to the Tonga tribe. The climate is sub-tropical, temperatures on the plateau varying from $90^{\circ} \mathrm{F} \quad\left(32^{\circ} \mathrm{C}\right)$ maximum to $40^{\circ} \mathrm{F}\left(4.4^{\circ} \mathrm{C}\right)$ minimum, with light frost in some areas in winter and an average rainfall of about $30 \mathrm{in}$. (75 $\mathrm{cm}$.); in the Gwembe Valley temperatures just over $100^{\circ} \mathrm{F}\left(37^{\circ} \mathrm{C}\right)$ may be experienced in a more humid climate.

Although no detailed survey of the incidence of leprosy has been made in the province, our records suggested that there was a higher incidence of the disease in the Gwembe Valley (before the Kariba development the people here were very primitive and malnutrition was almost universal among the children) and in the Kafue basin to the north (Namwala District).

The province is divided into 6 administrative districts, each under a District Secretary, and the local authorities are known as management boards (or municipal councils) in the towns and rural councils in the country areas. Each of these has a health councillor, with other health workers under him. Communications in the province are rather better than in most other parts of the country, as the railway and the Great North Road, the surface of which has steadily improved over the years until now it is "tarmac" throughout its length, traverse the whole length of the province. Various bus services now connect strategic points in the rural sectors with the towns, so that many patients who 10 to 15 years ago walked distances of up to 100 miles can now travel most of the way by train and bus.

The medical service of the province, which is under the supervision of the Provincial Medical Officer in Livingstone, comprises some 55 to 60 centres, ranging from the Central Hospital in Livingstone with some specialist facilities and the District Hospitals to small Rural Health Centres doing mainly out-patient work, plus a similar range of hospitals and dispensaries operated by 6 different missions.

A random sample survey of leprosy prevalence carried out by Ross Innes in 1949 revealed an incidence of 10.3 per 1000 in the Southern Province as compared with 12.6 per 1000 for the whole of the country (Innes, 1951). This survey was based upon the examination of 11,246 people in the province. No other leprosy survey covering this area appears to have been recorded.

I was based at The Salvation Army Hospital, Chikankata, near Mazabuka at the north-east end of the province. Here there is a general hospital, with nursing and laboratory training courses, which has developed rapidly over the past 15 years to a 250-bed hospital, as well as the leprosy work. Our leprosarium, which at one time accommodated 450 in-patients, was the leprosy treatment centre for the province. At no time, until recently, did we have more than 2 doctors at Chikankata, so that the organization of the leprosy control programme had to be very much a part-time exercise. For this reason, and because we had no extra staff, it was impossible at any stage to carry out a general survey of the incidence of leprosy and these limitations also dictated a pattern for our organization which involved a large degree of remote control.

There were 2 other leprosy treatment centres in the province at this time-both of which came into being rather haphazardly as "squatters" appendages to the District Hospitals at Gwembe-which served the Gwembe Valleyand Namwala. When our first efforts at a coordinated leprosy programme began in 1961, 
Gwembe had about 150 patients and Namwala about 40. No one at these centres had had any experience in leprosy and the overseeing given by frequently changing and over-worked government medical officers had usually been very scant. I began to pay monthly visits to Gwembe and later 3-monthly visits to Namwala; between these visits patients from the Namwala area were transported by road to Gwembe for examination.

Arrangements were made that all medical centres in the province would in future refer any suspected case of leprosy to one of the 3 treatment centres and no patient would be started on treatment until his case had been fully assessed and treatment prescribed by myself or my medical colleague from Chikankata. Out-patient treatment was also on a similar footing.

At Gwembe and Namwala we faced a formidable task. Records were either totally inadequate or non-existent, many healthy children of all ages were living freely in the leprosaria, many patients had the most appalling infected foot ulcers which had been treated only with the minimum of (unsterile) dressings, and there was little discipline among the patients. This is no reflection on those immediately responsible, for they had had thrust upon them a problem about which they knew little or nothing and were given virtually no facilities to deal with it.

A standard record card for leprosy patients was in use throughout the country and this had been carefully designed to meet all requirements. All patients' records were gradually brought up to date and full clinical details entered. During the assessment it was found that in many cases the disease was "burnt out" or clinically inactive and these patients were discharged to out-patient treatment or supervision. All the patients were receiving too high a dose of dapsone and this was reduced to a safe level. An all-out onslaught was made on the foot ulcer problem by teaching the sterile technique in the application of dressings, plaster, or other necessary surgical treatment and by teaching staff and patients the essentials in caring for anaesthetic feet and hands. One of the patients, a cobbler, was trained to make protective footwear and eventually we were well on the way to ensuring that all patients with anaesthetic feet had, and were wearing, microcellular rubber sandals made according to the Karigiri pattern. The incidence of foot ulceration fell steadily, partly as a result of treatment and preventive measures and partly also because in time patients learned to come for treatment at an earlier stage in the disease.

We were fortunate in having been able, before this time, to establish a pattern of total care of leprosy patients at Chikankata. Gradually this was extended to Gwembe and finally to Namwala. A small programme of occupational therapy had already been started at Gwembe and this was expanded with the enthusiastic help of the Medical Inspector in charge of this centre, without whose dedicated and intelligent support the whole provincial programme would have been impossible. The patients became more contented and so accepted more readily the stricter discipline being imposed to ensure regular treatment and a more peaceful community. All healthy children over the age of 2 years (younger when possible) were sent home to the care of relatives, and those who remained we put on to a register for the regular administration of dapsone prophylactically. This took time and persuasion to complete, but eventually the mothers recognized the benefits for their children.

As many patients who had been under treatment in the leprosaria for a number of years could now be discharged, so the inflow of new patients increased. The patients themselves and our own efforts in various parts of the province stimulated an interest in leprosy as a curable disease. The problem now was to ensure that those transferred to out-patient treatment continued with regular doses of dapsone, and that they would return for regular checks, at first 6-monthly and later yearly. This would reduce the relapse rate, which in turn would, we hoped, reduce the incidence rate. 


\section{AIMS OF THE PROGRAMME}

(1) Careful examination and assessment of every new patient with le prosy in the province

Transport was arranged-either public transport or ambulance-from the centre to which they first reported to one of the 3 leprosaria. Only when active leprosy had been confirmed and laboratory investigations completed was treatment started. Similarly, all out-patients reported to one of these centres for their routine re-assessments.

(2) The establishment of regular leprosy clinics at each of the medical centres in the province

For the treatment of out-patients in their area, the government leprologist issued special registers (shared with tuberculosis patients), and periodic checks to see that they were properly kept were made during visits by the P.M.O., Medical Officers, leprologist or myself. We decided that, except in special cases like proved responsible teachers, no patient should be given dapsone to take at home. Patients were prescribed either a weekly supply of dapsone tablets if they lived within 5 miles of a medical centre, or fortnightly injections (5 to 10 miles) or monthly injections if over 10 miles. These distances were only approximate and depended upon such factors as age, degree of crippling, geographical obstacles (e.g. rivers in flood), and availability of public transport, but this system meant that we could be sure that if patients attended regularly they received their dapsone regularly. A provincial leprosy register has now been compiled showing details of every leprosy patient in the province, including details of treatment and dates of re-checks. It is hoped eventually to follow up all patients who have not presented themselves for re-checking.

\section{(3) Ensuring regular treatment of all patients}

In addition to the scheme outlined above, we tried by means of visits, letters, telephone calls, and any other means possible, to impress on all concerned the importance of regular treatment, and adequate follow up of non-attenders. Had it been possible to devote the time to regular touring we could have achieved a high degree of co-operation more quickly, but through the excellent support of the territorial leprologist, the P.M.O. and other health officials and by using most journeys undertaken as an opportunity to make personal calls at medical centres, the message was gradually put across. From the beginning we set the standard as $100 \%$ regular attendance for all patients, as it was found that too many of the medical staff were prepared to accept a much lower attendance rate that was not compatible with adequate treatment. Local authorities, including many of the chiefs, were enlisted in this effort, so that when a patient absconded or failed to attend regularly for treatment there were a number of alternatives available whereby he could be followed up. Recalcitrant patients were brought back into a leprosarium for a period of "re-education and re-establishment of treatment". The message was soon understood by a high proportion of the patients! Many also saw the value of continued treatment, and for some the clinics became social occasions for meeting old friends. A frequent source of difficulty was that certain patients, in their anxiety to return to their home, insisted that they lived within a reasonable distance of a treatment centre, but later it was found that they lived much farther away and could not be expected to continue regular journeys. The word "near" to the African could mean anything up to 50 miles! By use of a cyclostyled letter-form addressed to some responsible authority in the area concerned, such as a health councillor, district secretary, or local hospital or mission, we sought and obtained exact information on distance and on any special problems before a patient was considered for out-patient treatment. More recently government appointed leprosy and tuberculosis home visitors were appointed through a scheme devised by the tuberculosis and leprosy specialists. These home visitors were attached to strategic hospitals and could by bicycle cover a wide area, following up contacts and non-attenders, carrying out BCG vaccination, and keeping records, as well as encouraging 
the co-operation of officials at all levels and referring any new patients they discovered to the nearest treatment centre. This is the first step towards mobile units, which are so valuable in any scheme of this type. Their effectiveness will be enhanced when a better calibre of home visitor becomes available. At this stage of the country's development suitable personnel are still in short supply.

\section{(4) Detection and treatment of early cases of the disease}

Here again not only did we try to impress on all medical personnel concerned the importance of early treatment and the essentials of diagnosis, but we also used the officials previously mentioned to foster a response from the patients. In this effort we were aided by the obvious ability of the ordinary villager to diagnose leprosy, even in its earliest phase. This ability, which has been noted by many other workers, is sometimes almost uncanny. All that is required, therefore, is to break down prejudice and misunderstanding and to do everything possible to minimize the disruption of normal life through attending for treatment. Education to reduce the stigma and the feeling of hopelessness attached to leprosy was needed. There were delays in plans for the production of posters, but I was able to speak to chiefs and other officials at local authority meetings and, to a limited extent, in schools. The former had the value of a 2 -way exchange whereby we learnt some of the fears and genuine obstacles in the way of a patient coming for treatment. For example, the 2 government leprosaria had no segregation of the sexes in their overall arrangement of houses. For some time we had fought against various types of immorality occurring in leprosaria, in order to restore self-respect to the patients, increase the peace and happiness of the majority of them, and reduce the birth rate of healthy babies in an infected area. (It is a curious commentary on the "unconscious", attitude towards leprosy and its sufferers that intelligent people who would never dream of permitting a potentially degrading arrangement like this for patients with other diseases should tolerate it in regard to leprosy.) The African officials pointed out that we could hardly expect husbands to allow their wives to come for treatment-or at least not until the disease was far advanced-when it was likely to mean that a male patient might readily take her as a temporary wife. The position was soon remedied by taking steps to re-organize the leprosaria. In return we sought the help of the chiefs in stopping their practice of granting divorce on the sole grounds that the spouse was being treated for leprosy. They have now stopped doing this. Recognition that admission to a leprosarium may lead to a break up of a family, the loss of subsistence livelihood, with suffering for dependants, and the steps to be taken to prevent these consequences are an essential part of leprosy treatment and control. Therefore, the co-operation of chiefs, village headmen, local authority officials, and employers was enlisted to see that a man's cattle or land were looked after during his absence for treatment, that his wife and family were cared for, that his job was kept open or there was a reasonable promise of a job waiting for him on discharge. Progress in this respect was slow, but we found that employers, including the government departments concerned, were often very helpful with jobs. We finally came to the conclusion that the evils engendered by admission to a leprosarium might be greater than the effects of the disease itself, and therefore increasing emphasis has been laid on out-patient treatment at an early stage. The knowledge that admission to a leprosarium would be for a brief period only, or not necessary at all, is the best encouragement to patients to seek early treatment.

(5) Training medical personnel in the essential facts of leprosy and its control

Apart from the remote control methods referred to above and periodic circulars sent out through the P.M.O., the only other methods that proved practical were on-the-spot teaching during random visits, and the attendance of nurses, doctors and other health officials as occasion offered at our major clinics at one of the leprosaria in order to learn what they could. 
Unfortunately these clinics were of such marathon proportions-lasting from early morning to dusk and seeing up to 100 new patients and re-checks in a day-that there was little time for teaching. An effort to arrange 1 - or 2-day seminars at opposite ends of the province on different occasions for those responsible for leprosy care proved unworkable because of staff shortage at the smaller centres.

\section{(6) Health education in leprosy}

Much more could and should be done in this field, but we were encouraged by the measure of response that the methods described (4) produced. The emphasis was on early treatment to ensure early cure and avoid deformity and crippling, the safety of patients on out-patient treatment so that they could return to a normal life in society and be able to do a job, and stressing the fact that leprosy is just another disease which can be treated within a normal hospital system. School-teachers began to refer to us children whom they had discovered with suspicious patches, and the same teachers proved the most ready to accept children back into their classes when the latter were transferred to out-patient treatment and they sometimes helped by administering the dapsone tablets to the child themselves. At Chikankata we had a school for children with leprosy, including all the grades of primary school, which at one time had an enrolment of 120 . Today there are very few children left in the leprosarium to go to school as most are now referred early for out-patient treatment and attendance at a normal school. A few children completed primary school education while in the leprosarium and were bright enough to qualify for a place in secondary school. There is a large secondary boarding school at the Mission and we eventually persuaded the school authorities to make an exception by accepting a child patient for school while he continued to live in the leprosarium. We were at first uncertain as to what would be the reaction of teachers and other children, but the steady education on leprosy had obviously had its effect and the child was fully accepted. Since then, others have proceeded to secondary schooling in this way. As we see it, there is no reason why in future there should be any special schools for leprosy sufferers who, if in-patient treatment is indicated, should be able to attend the local school. It has been our policy to employ patients for almost all the unskilled jobs (and a few skilled jobs) in and around the hospital, including ward cleaning, but not kitchen and laundry work. Public opinion is not yet ready, we feel, to accept leprosy patients in the two last-named departments. All along such moves have been questioned by the local population, by patients in the hospital, and also by higher authorities and we have tried to take these people into our confidence by explaining why it is safe. The same is true of the admission of leprosy patients to hospital beds and most people have come to accept the situation, but we believe that accelerating these progressive moves unduly could antagonize the public to the point of losing confidence in us. In a sense, the reverse problem has been faced with the healthy children of mothers with leprosy. As a result of the policy of keeping small children with their mothers in the government leprosaria, the government leprologist and I have both seen a number of children who have developed signs of the disease before the mother was discharged. At Chikankata we established a purpose-built nursery where young children were cared for under the over-all supervision of the Sister-inCharge of the leprosy settlement. The nursery was staffed by at least one trained enrolled nurse and a group of pre-nursing candidates, and when mothers came in to feed and play with their children at specified times they wore long-sleeved gowns and masks to reduce skin and nasal contact. The children were given prophylactic dapsone and BCG vaccination and no case of leprosy has been diagnosed in 8 years. The recent work of Pedley (1967) who demonstrated the presence of Myco. leprae in the breast milk of women with lepromatous leprosy suggests that the only advantage of this elaborate routine may be the certainty of a regular prophylactic dose of dapsone. The 
difficulty of ensuring this in an open leprosarium is, I feel sure, the explanation for the incidence of leprosy in apparently healthy children in the Government leprosaria. The nursery system enabled us to teach mothers child care and proper weaning diets and to give each child a full range of preventive inoculations, but cross infections of various origins caused repeated anxiety. Psychologically the ideal is, of course, for the mothers to keep their children, but one bears in mind that the child is exposed not only to the mother's bacilli but to those of the other patients as well. Again one comes back to the desirability of out-patient treatment.

\section{RESULTS}

The success of any control scheme will ultimately be assessed on the incidence of disease in the area concerned. Over the last 4 years (provincial figures of notifications were not available before 1965), that is, the 4 years after the inception of a co-ordinated treatment plan, there has been a steady decline in the 6-monthly and annual notifications of new cases of leprosy (see Fig. 1). The rate of reduction is greater than the $15 \%$ per annum which might be expected (Browne, 1962). Some reduction might be expected after a "pool" of long-standing cases had been located and placed under treatment in

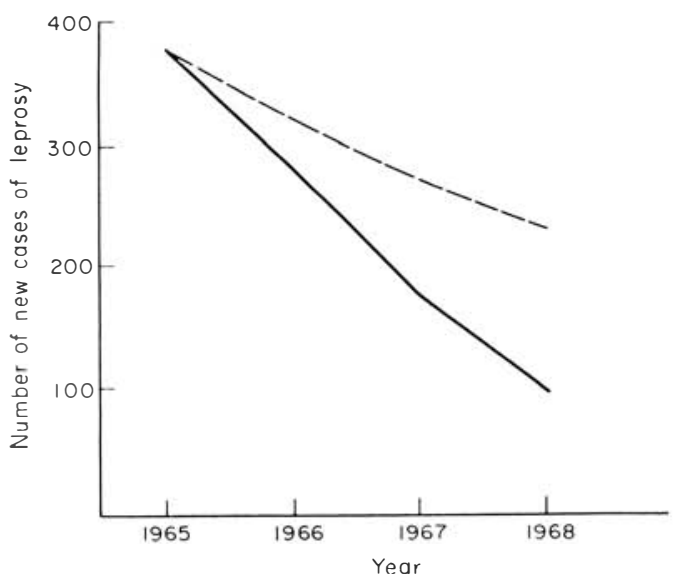

FIG. 1

Incidence of leprosy in the Southern Province of Zambia. - , Notifications per year; - - -, expected notifications $(15 \%$ decrease per year).

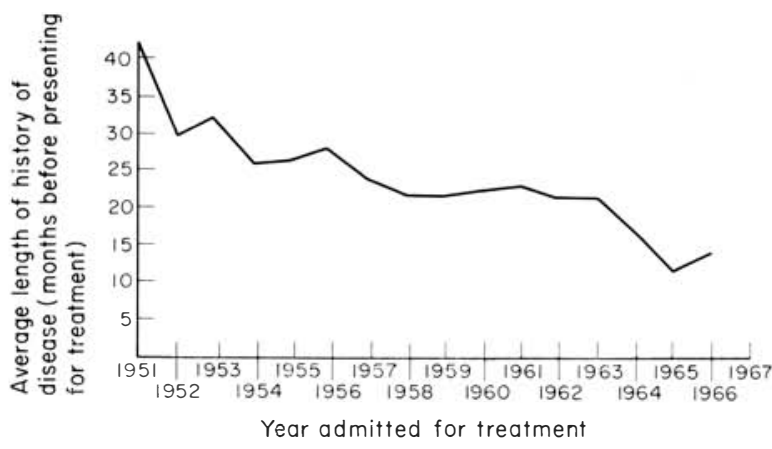

FIG. 2

Average length of history of disease in patients admitted to Chikankata leprosarium.

the early years of the programme, but the reduction in incidence, which could almost be called dramatic, has continued. It has also to be borne in mind that more intensive efforts to diagnose leprosy earlier would tend to influence notification rates in the opposite direction. An analysis of the average interval between the first onset of disease signs to presentation for treatment of patients admitted to Chikankata in any given year shows a steady reduction. While the history given by patients cannot be considered very accurate, especially in respect of time intervals, this inaccuracy would be expected to remain constant throughout the period under review. Fig. 2 shows that the average length of history has been reduced from 41.5 months in 1951 to 14 months in 1967 . This means not only that healthy members of the population will be exposed to infectious disease for shorter periods (and to a lower bacillary concentration in the case of lepromatous patients) and will therefore be less likely to contract the disease, but also that some complications of the disease will become less common. Fig. 3 shows that the incidence of deformity-including claw hand, loss of digits, other forms of bone destruction, and foot ulceration-in patients admitted to the Chikankata leprosarium fell sharply before the inception of the provincial control programme when leprosy treatment first began at Chikankata, and that thereafter there was a slight but fairly steady decline. 


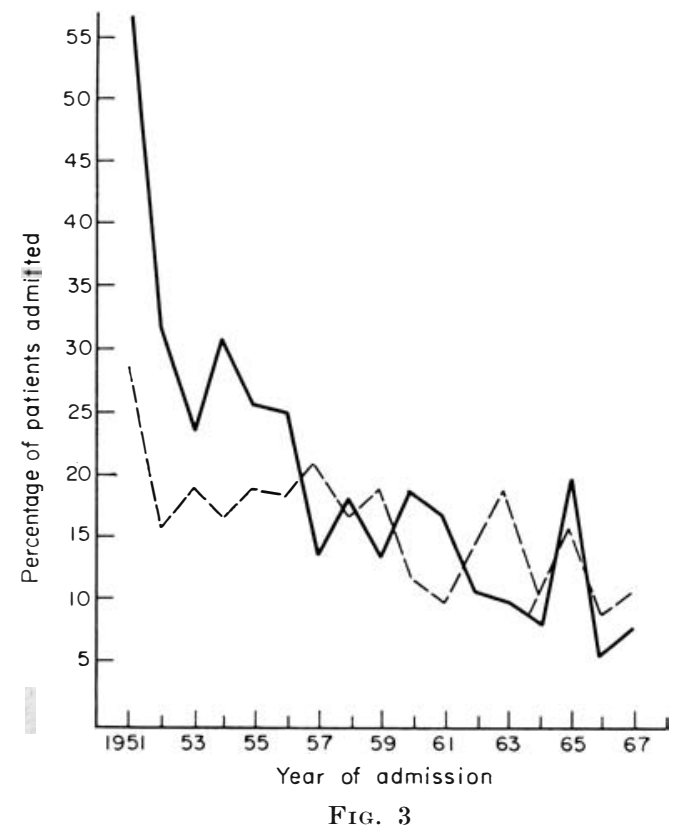

Incidence of deformity and foot ulceration in patients admitted to Chikankata leprosarium. -, Deformity; --- , foot ulceration.

Partly on account of the steady reduction in incidence of leprosy in the province and presentation for treatment of the disease at an earlier stage, the number of in-patients under treatment has been markedly reduced. From a maximum of 768 in-patients in the 3 leprosaria in 1964 there has been a reduction to just over 300 in 1968, and the Namwala leprosarium has been closed. This reduction represents a considerable saving in treatment costs and in the disruption of normal living. Fig. 4 shows the steady reduction in the length of in-patient treatment of patients admitted to Chikankata in the period 1955 to 1967 . The duration of in-patient treatment could be reduced still further were it not for the problem of the sparsely scattered distribution of the population and the consequent difficulty in providing adequate medical coverage. Many patients are still in leprosaria who could be on out-patient care if they were near enough to a treatment centre. The effectiveness of out-patient treatment may be gauged by the fact that a survey carried out in 1967 showed a regular attendance rate of

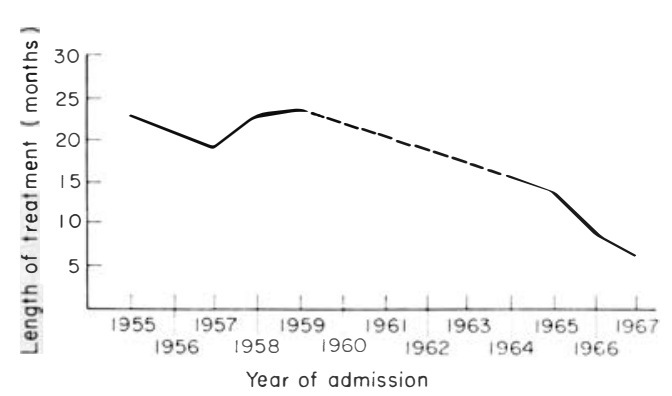

Fig 4

Average length of in-patient treatment of patients admitted to Chikankata leprosarium.

over $70 \%$ at the 55 medical centres in the province. While there is obviously still room for improvement, this figure compares favourably with similar results in other reported control schemes (ranging from 59 to $70 \%$ ). The remote control necessarily used in our scheme owing to lack of staff and finance is an obvious disadvantage, but if this attendance rate can be achieved by the method used a further improvement should be possible if and when mobile units can be brought into operation. Furthermore, the system of dapsone distribution employed by us means that over $70 \%$ of all out-patients are actually taking dapsone regularly.

\section{DISCUSSION}

The control programme described was not the programme of choice but one of expediency. The cost in terms of money has been almost negligible and was more than offset by the saving in reduction of the number of institutionalized patients. It is felt that good progress has been made in 7 years towards the complete control of leprosy in the Southern Province of Zambia, but this could not have been accomplished without the hard work and enthusiasm of a team of workers in various fields and also the increasingly encouraging co-operation between Government, mission, and local authority personnel as well as that by the patients themselves. The progress could have been achieved in an even shorter time had the facilities we desired been available in the early stages of the programme. We had the 
advantage of better road and rail communications than most of the other Zambian provinces, and therefore better medical coverage; but on the other hand the population of this area is probably more backward and less cooperative than some of the tribes in other provinces. Last year LEPRA launched a control programme in the Eastern Province run by a mobile team under an experienced leprosy worker and designed to improve out-patient treatment, carry out systematic case finding, and provide increased publicity and health education. This is already proving very effective and has enabled many patients who would otherwise be too far from a treatment centre to be maintained on an out-patient régime. The LEPRA Pilot Leprosy Control Project in Malawi working with a much more compact population (500 per sq. mile) in an area of only 2000 sq. miles and an estimated incidence of leprosy of 10 to 12 per 1000 is using 3 mobile teams (LEPRA Annual Report, 1966, pp. 6 and 7 ). This excellently planned project involves a considerable capital and maintenance cost, but is effecting a very thorough coverage of the entire population and is aiming at eradicating leprosy from the area. This it may be able to achieve in a relatively short time. The more gradual control scheme described above, by reducing the sources of infection at the rate at present indicated, stands to achieve a similar result but will require a longer time.

Our ultimate aim is to be able to treat all patients on an out-patient basis from the beginning, or at least after only a short period to allow for stabilization, and admit only those patients with complications-such as reactions or ulceration-for treatment in the leprosarium. However, until some form of mobile unit is in operation this will not be possible with our scattered population. We should endeavour to carry out some sort of systematic examination, together with $\mathrm{BCG}$ vaccination, of at least the more vulnerable part of the population, that is, the children and family contacts of known cases. To date, little in the way of contact examination has been possible.
With an ever-increasing proportion of Zambia's children being able to attend school (by 1972 it is hoped to provide universal primary schooling) systematic medical examinations at school, probably combined with other health surveys or vaccination, should detect early disease in this important sector of the population.

When about to embark on this control scheme there was an opportunity to obtain training in surgical techniques for the correction of deformity in leprosy. We felt that the control approach should have priority and the results to date suggest that the amount of correctable foot and hand deformity will steadily decrease. In Zambia, at least, unlike India, there is little stigma attached to the claw hand and provided that a person can grip a plough or a cooking pot reasonably well he feels little disadvantage. The degree of co-operation of most of the patients is such that subsequent carelessness will often ruin a carefully repaired hand. However, plans were laid for a limited surgical programme for rehabilitation at another mission hospital in the province and the doctor there has been to Karigiri, India, for training. At present simple physiotherapy-mainly concentrated at the leprosaria, but simple exercises also carried out at out-patient clinics-can make some contribution to preventing deterioration in a paralysed hand or foot.

Perhaps the most encouraging feature of our results has been the high out-patient attendance rate achieved, despite the absence of field workers to carry out effective follow-up, and the high limit we set as the maximum distance from home to treatment centre for out-patients (other projects have set limits of 3 to 5 miles). An effective measure of co-operation from chiefs and local authorities was not easily achieved and still leaves much to be desired, but we have demonstrated that mobilization of all existing resources both within and outside the health services can be worth while and in this instance was essential. No generalizations can be made. It is obvious that not only was this programme not ideal but it would not necessarily 
prove as successful in other situations. It cannot be described strictly as a control project, but it constitutes a co-ordinated treatment programme which appears to be achieving a useful measure of control of leprosy in a scattered population with a relatively low incidence of the disease. There is still a great amount of ignorance and prejudice about leprosy in Zambia and there is need for intensive education if complete control is to be achieved. It is hoped that the LEPRA project in the Eastern Province will achieve what we have failed to achieve, in an area with an identical incidence of leprosy according to Ross Innes's survey (Innes, 1951).

\section{SUMMARY}

A co-ordinated treatment programme for leprosy in the Southern Province of Zambia is described and its results in terms of control of the disease in the area are assessed. Despite absence of adequate funds and extra personnel it is suggested that this limited programme is achieving a useful degree of control. Cooperation is the key to success.

\section{ACKNOWLEDGEMENTS}

Thanks are expressed to all members of the team who have enthusiastically co-operated in our programme over the years, including the P M.Os concerned. In particular I would thank our own staff at Chikankata, and especially Sister Elizabeth Gaimer for the statistics she has compiled and to Dr. Colin McDougall, the present Government leprologist in Zambia, for his co-operation. Grateful acknowledgement is made of the consistent encouragement given by the late Dr. P. Glyn Griffiths who was the Government leprologist during most of the formative period of this programme.

\section{REFERENCES}

Browne, s. G. (1962). Leprosy in Africa today. Brit. Postgrad. Med. .J. 38, 86.

INNES, J. ROSS (1951). Leprosy in N. Rhodesia. East Afr. med. .J. 28, 1, 21 .

LEPRA ANNUAL REPORT (1966), pp. 6, 7.

PEDley, J. C. (1967). The presence of Myco. leprae in human milk. Lepr. Rev. 38, 4, 239.

PEDLEY, J. C. (1968). The presence of Myco. leprae in the lumina of the female mammary gland. Lepr. Rev. 39, 4, 201. 